\title{
Determination of deformation properties of soils as input parameters for calculation
}

\author{
Eva Panulinova ${ }^{1, *}$, Slavka Harabinova $^{2}$ \\ ${ }^{1,2}$ Technical University of Kosice, Faculty of Civil Engineering, Institute of Structural Engineering \\ Vysokoskolska 4, 04002 Kosice. Slovakia
}

\begin{abstract}
When designing the foundations of any building structure, it is important to know not only the load of the structure, but also the deformation characteristics of the subsoil. Their underestimation leads to incorrect design of the foundations or even to failures, the reparation of which requires considerable financial costs. The real values of the deformation soil properties gained from the geotechnical investigation often do not match the tabulated values used in the design. In this contribution, actual and tabular values of selected soil properties in the bedrock in the locality of Kosicka kotlina are compared. Simple buildings designed according to the 1st geotechnical category are in the described location predominantly based on Neogene clay of intermediate plasticity class F6 and less on clays class F8. These are soils sensitive to changes in their natural moisture - they swell when exposed to water, thus become unstable. It is therefore important to use the most accurate values in the calculation of the foundations. The analysis of 130 measured values confirmed that $52 \%$ of the all measured values are outside the indicative table data. The use of inaccurate input values can bring a risk and threat to safety, reliability and proper use of any construction. It is therefore necessary to carry out the appropriate geotechnical investigation of soils for all types of buildings.
\end{abstract}

\section{Introduction}

Each engineering structure must be designed in accordance with the Eurocodes (EC), not excluding the geotechnical structures for which Eurocode 7 [1] applies. Constructions are assessed according to the theory of limit states; if these limit states are exceeded the construction is no longer reliable and safe. This means that all geotechnical constructions must be designed and constructed in such a way as to transfer all loading and load effects during their lifetime [2]. The deformation of the base soil is transmitted retroactively to the construction and may cause its failure or damage.

In the process of design or optimisation of geotechnical structures, the characteristics of the natural environment must be determined as accurately as possible in order to establish a reliable calculation model of the structure $[3,4]$. In spite of this, a detailed geotechnical investigation is not always carried out, mainly because of lack of time or money.

*Corresponding author: eva.panulinova@tuke.sk 
The most commonly registered failure of constructions is a disproportionate settlement, which is assessed within a Group II of limit states - serviceability limit states [3, 4]. It should be proved that the design load on the bedrock would not cause such settlement of a building which would unduly restructure or change the position of the structure in such a way that the normal use and purpose of the construction are disproportionately impeded.

Depending on the complexity of the construction and its foundation conditions and on the standards used, the design and assessment methodology is divided into three categories $[1,2]$.

For the preliminary design (Geotechnical Category 1) indicative values of the soil characteristics can be used. These are:

- determined statistically as average, their size is given by the interval,

- valid for the entire Slovak Republic, without localization,

- probably lower than the real one at the site under consideration, if we focus on the deformation properties.

Since the real values of the deformation properties gained from the geotechnical investigation often do not match the used tabulated values, this may result in the higher costs of the foundation structure. The aim of this paper is to compare actual and tabular values of selected soil properties in the subsoil/bedrock in the selected locality.

\section{Deformation properties of soils in the selected area}

In order to determine / calculate the settlement of construction properly we need to know the deformation characteristics of soils throughout the so-called deformation zone.

It is the point below which the effect of overload on settlement no longer occurs [3]. Under field conditions, the above-mentioned properties are represented by the Young's Modulus $\left(E_{d e f}\right)$, under laboratory conditions it is the Oedometric modulus $\left(E_{\text {oed }}\right)$.

The Oedometric modulus generally tends to increase its value with increasing stress. Therefore, it should be considered separately for each layer, taking into account the range of initial and final stresses [5].

The conversion between the modulus of deformation $E_{d e f}$ and the modulus of oedometry $E_{\text {oed }}$ is given by the following relation [6]:

$$
E_{\text {def }}=\beta . E_{\text {oed }} \quad \beta=1-\frac{2 v^{2}}{1-v}
$$

in which $v$ stands for Poisson number.

\subsection{Kosicka kotlina as selected area}

The Kosice Basin/ Kosicka kotlina was chosen for the analysis, as a locality that is directly related to the authors' home and workplace. According to the geomorphological division of Slovakia, the Kosice basin is situated in the south-eastern part of Slovakia, and it has an elongated shape from the north to south as shown in Fig. 1.

The Kosice basin has a lowland character; it is located in a tectonically lowered area, where quaternary sediments of greater thickness occur. Its development began at the end of the Paleogene and the beginning of the Neogene [7]. It is characterized by simple geological composition and river relief, which was created by the rivers Torysa, Hornad, Bodva, and Ida. It is divided into three units - Kosice Plain/rovina, Toryska and Medzev Highlands. Most of the area is occupied by the Kosice Plain, which is formed by a wide river floodplain (in some places up to $5 \mathrm{~km}$ ) created by the Hornad River. The Kosice Plain has a typical flat relief with the residues of river terraces, abandoned river beds and meanders of the Hornad River. It is characterized by wide floodplains [7]. 
The geological structure in the lower layers is built mainly of Neogene clays, which in some places protrude to the surface or are covered with Quaternary river sediments.

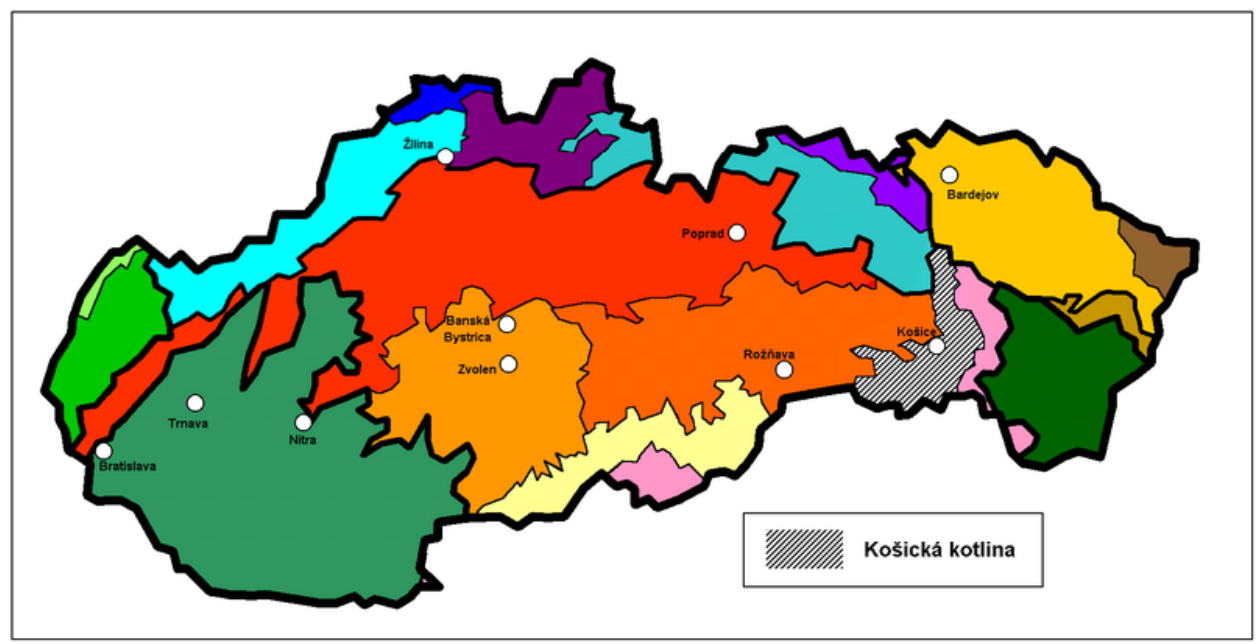

Fig. 1. Map of geomorphological units in Slovakia - Kosicka kotlina [8].

Simple buildings designed according to the 1st geotechnical category (GC) are in the described location predominantly based on of Neogene clay of intermediate plasticity class F6 and less on clays class F8. It should be taken into account that these are soils sensitive to changes in their natural moisture, which means that they swell when exposed to water, thus becoming unstable in volume their properties are changed. It is therefore important to include the most accurate values in the calculation of the foundations.

\subsection{Material and methods}

The analysis is focused on the assessment of deformation characteristics of soils, which are most often found in the depth of interest. Geographical investigation reports were provided by the companies GEOSlovakia s.r.o. and Bestin s.r.o. (both based in Kosice), and Geo archive at the BERG TUKE Faculty. The measured values of soil properties in various localities of the Kosice Basin were taken from the archive materials. For the pre-selected soils, which occur most frequently in the monitored area, the data were processed and divided into three groups [9].

The observed soils:

- $\quad \mathrm{CH}$ - Clay of high plasticity, plastic, semi-plastic and semi-solid consistency (category F8),

- CI - Clay of intermediate plasticity, semi-plastic and semi-solid consistency (category F6),

- CL - Clay of low plasticity, semi-plastic consistency (category F6).

Altogether 130 soils were evaluated for which the following data were recorded (in some cases calculated):

- location of the drilling;

- soil class and depth,

- Oedometric modulus $\left(E_{\text {oed }}\right)$, factor $\beta$,

- Liquidity index (Ic), which was used to determine consistency,

- Plasticity index (Ip), on the basis of which plasticity was determined. 
The data were divided into tables based on plasticity and consistency and compared with baseline values [10] (Table 1. and Table 2.).

Table 1. Comparison of measured and table values $E_{\text {def }}$ regardless consistency.

\begin{tabular}{|c|c|c|c|c|c|}
\hline \multirow[b]{2}{*}{ Soil } & \multirow{2}{*}{$\begin{array}{c}\text { Interval of } \\
\text { measured values } \\
\boldsymbol{E}_{d e f} \\
{[\mathrm{MPa}]}\end{array}$} & \multirow{2}{*}{$\begin{array}{c}\text { Interval of } \\
\text { table values } \\
\boldsymbol{E}_{d e f} \\
{[\mathrm{MPa}]}\end{array}$} & \multicolumn{3}{|c|}{$\begin{array}{l}\text { Number of deformation module values } \\
\qquad\left(E_{d e f}\right)\end{array}$} \\
\hline & & & Measured & $\begin{array}{l}\text { Within table } \\
\text { interval }\end{array}$ & $\begin{array}{c}\text { Outside } \\
\text { table } \\
\text { interval }\end{array}$ \\
\hline CH-F8 & $1.3246-6.5786$ & $2-8$ & 46 & 29 & 17 \\
\hline CI-F6 & $1.9975-15.5476$ & $6-12$ & 79 & 29 & 50 \\
\hline CL-F6 & $3.8305-6.6834$ & $3-6$ & 5 & 4 & 1 \\
\hline Total & - & - & 130 & 62 & 68 \\
\hline Total [\%] & - & - & 100 & 48 & 52 \\
\hline
\end{tabular}

Table 2. Comparison of measured and table values $E_{d e f}$ sorted by consistency.

\begin{tabular}{|c|c|c|c|c|c|}
\hline \multirow{3}{*}{ Consistency } & Soil & Measured & $\begin{array}{c}\text { Within table } \\
\text { interval }\end{array}$ & $\begin{array}{c}\text { Outside } \\
\text { table } \\
\text { interval }\end{array}$ & $\begin{array}{c}\text { Number of deformation module values } \\
\text { interval in } \\
{[\%]}\end{array}$ \\
\cline { 2 - 6 } & & & 18 & 10 & 36 \\
\hline \multirow{3}{*}{ Firm } & CH-F8 & 28 & 22 & 47 & 68 \\
\cline { 2 - 6 } & CI-F6 & 69 & 0 & 0 & 0 \\
\cline { 2 - 6 } & CL-F6 & 0 & 10 & 5 & 33 \\
\hline \multirow{3}{*}{ Solid } & CH-F8 & 15 & 7 & 3 & 30 \\
\cline { 2 - 6 } & CI-F6 & 10 & 4 & 1 & 20 \\
\cline { 2 - 6 } & CL-F6 & 5 & 1 & 2 & 67 \\
\hline \multirow{3}{*}{ Soft } & CH-F8 & 3 & 0 & 0 & 0 \\
\cline { 2 - 6 } & CI-F6 & 0 & 0 & 0 & 0 \\
\cline { 2 - 6 } & CL-F6 & 0 & 62 & 68 & - \\
\hline \multicolumn{2}{|c|}{ Total } & 130 & & \multicolumn{2}{c}{} \\
\hline
\end{tabular}

\section{Results and discussion}

As part of the analysis a more detailed comparison of data with respect to soil class and consistency is presented in the Table 2 and we can see the following:

- for the soils CI grade F6 of firm consistency, $68 \%$ of the measured data were outside the guideline interval,

- the similar conclusion applies to the CH-F8 soil, but this is incomparable, as the monitored sample consisted of only 5 values.

- deviations of about 33\% were observed for CH-F8 of firm consistency and $\mathrm{CH}$ F8 and CI-F6 of solid consistency,

- $52 \%$ of the 130 measured values were out of the guideline interval.

The results were further analysed from the point of view of the ground plan design for the $1^{\text {st }}$ geotechnical investigation, where the design is usually dependent on the soil class measured in the point about $2.0 \mathrm{~m}$ deep. From the total number of 68 measurements there were 33 of them outside the interval of the baseline values, which is $48.5 \%$. 


\section{Conclusion}

The results of the analysis confirmed that $52 \%$ of the all measured values are outside the indicative table data; this is more than the half of the monitored data. It can therefore be stated that there is a risk due to the use of inaccurate input data, which may lead to incorrect design of the dimensions of the foundation structure, resulting in defects transferred from the subsoil to the structure.

Uneven or additional settlement of buildings cracks on the buildings facades, filled in or flooded construction pits are just some examples of failures that can be caused by neglect or even omission of geotechnical investigation. Many designers or contractors have experienced a senseless cost-saving approach where the cost of troubleshooting often exceeds the cost of conducting of the geotechnical investigation.

Although the geotechnical investigation is not prescribed by the Building Act, it is an important basis for the design of buildings. Only on the basis of the relevant data the structural engineer can design a building foundation construction correctly. It is therefore necessary to carry out the appropriate geotechnical investigation of soils for all types of buildings. Such approach will contribute to a more optimum, safer and more cost-effective design and avoid possible complications and damage to the construction and use of buildings.

This work was supported by the Scientific Grant Agency of the Ministry of Education of Slovak Republic under Project VEGA 1/0374/19.

\section{References}

1. Eurocode7 Geotechnical design, EN 1997:2004

2. J. Frankovska, at all., Foundation of buildings (STU Bratislava, 2011)

3. P. Turcek, J. Hulla, Foundation (in Slovak), (Bratislava: JAGA GROUP, 2004)

4. M. Drusa, at all., Design and control of earth structures of road construction (in Slovak), (EDIS, 2013)

5. I. Vanicek, Geomechanics: Soil mechanics (in Czech), (Praha, CVUT, 2000)

6. J. Jesenak, Soil mechanics (in Slovak), (STU Bratislava, 1994)

7. J. Kostalik, Genesis and stratigraphy of the Kosice basin sediments in light of new research Geomorphologia Slovaca et Boehmica, 2 (2007)

8. Geological map of Slovakia, (Online), http://apl.geology.sk/gm50js/

9. P. Tothova, Deformation properties of soils depending on their genesis (in Slovak), Bachelor thesis, (TUKE, 2018)

10. STN 731001. Geotechnical design, Appendix 5, (1987) 